\title{
BMJ Open Shifting gears versus sudden stops: qualitative study of consultations about driving in patients with cognitive impairment
}

\author{
Carol Sinnott, ${ }^{1}$ Tony Foley, ${ }^{2}$ Linda Horgan, ${ }^{3}$ Kathleen McLoughlin, ${ }^{2}$ \\ Cormac Sheehan, ${ }^{2}$ Colin Bradley ${ }^{2}$
}

To cite: Sinnott C, Foley T, Horgan L, et al. Shifting gears versus sudden stops: qualitative study of consultations about driving in patients with cognitive impairment. BMJ Open 2019;9:e024452. doi:10.1136/ bmjopen-2018-024452

- Prepublication history and additional material for this paper are available online. To view these files, please visit the journal online (http://dx.doi. org/10.1136/bmjopen-2018024452).

Received 30 May 2018 Revised 29 July 2019 Accepted 30 July 2019

Check for updates

(c) Author(s) (or their employer(s)) 2019. Re-use permitted under CC BY-NC. No commercial re-use. See rights and permissions. Published by BMJ.

${ }^{1}$ Department of Public Health and Primary Care, University of Cambridge, Cambridge, UK ${ }^{2}$ Department of General Practice, University College Cork, Cork, Ireland

${ }^{3}$ Department of Occupational Therapy, University College Cork, Cork, Ireland

Correspondence to

Dr Carol Sinnott;

cs926@medschl.cam.ac.uk

\section{ABSTRACT}

Objective General practitioners (GPs) report finding consultations on fitness to drive (FtD) in people with cognitive impairment difficult and potentially damaging to the physician-patient relationship. We aimed to explore GP and patient experiences to understand how the negative impacts associated with FtD consultations may be mitigated.

Methods Individual qualitative interviews were conducted with GPs $(n=12)$ and patients/carers $(n=6)$ in Ireland. We recruited a maximum variation sample of GPs using criteria of length of time qualified, practice location and practice size. Patients with cognitive impairment were recruited via driving assessment services and participating general practices. Interviews were audiorecorded, transcribed and analysed thematically by the multidisciplinary research team using an approach informed by the framework method.

Results The issue of FtD arose in consultations in two ways: introduced by GPs to proactively prepare patients for future driving cessation or by patients who urgently needed a medical report for an expiring driving license. The former strategy, implementable by GPs who had strong relational continuity with their patients, helped prevent crisis consultations from arising. The latter scenario became acrimonious if cognition had not been openly discussed with patients previously and was now potentially impacting on their right to drive. Patients called for greater clarity and empathy for the threat of driving cessation from their GPS.

Conclusion GPs used their longitudinal relationship with cognitively impaired patients to reduce the potential for conflict in consultations on FtD. These efforts could be augmented by explicit discussion of cognitive impairment at an earlier stage for all affected patients. Patients would benefit from greater input into planning driving cessation and acknowledgement from their GPs of the impact this may have on their quality of life.

\section{INTRODUCTION}

For older adults, driving cessation can limit access to family, friends and services and is an independent risk factor for entry to a nursing home. ${ }^{1}$ General practitioners (GPs) may be wary of consultations on medical fitness to
Strengths and limitations of this study

- This multiperspective qualitative study examined the experiences of both healthcare professionals and patients with cognitive impairment to understand both sides of sensitive consultations on medical fitness to drive in the setting of cognitive impairment.

- The transferability of our findings is enhanced by a maximum variation sample of general practitioners (GPs) in terms of different practice contexts (large vs small group practices, urban vs rural locations) and variable levels of professional experience.

- The validity of interviews with GPs was enhanced by using the technique of chart-stimulated recall.

- We found that engaging older patients with cognitive impairment in our research was challenging and countered this by expanding approaches to recruitment.

drive (FtD) because of potential negative impacts on a patient's sense of autonomy, quality of life and the doctor-patient relationship. ${ }^{2}$ This discomfort is amplified in patients where there is concern about cognition, as GPs can also be reluctant to address the earlier stages of cognitive impairment with older patients due to fear of causing unnecessary anxiety, labelling and stigma. ${ }^{3}$

Cognitive impairment exists across a spectrum from mild cognitive impairment to mild, moderate and advanced dementia. Prevalence estimates for these conditions vary by study design and population examined, but approximations for the prevalence of mild cognitive impairment in older adults (aged over 50 years) are 6\%-20\% and those for dementia are $4 \%-7 \%$. While not all patients with mild cognitive impairment go on to develop dementia, approximately $10 \%$ per year do progress, with the majority of these people experiencing decline in driving abilities over time. ${ }^{2} 4$ Cognitive decline is associated with crash risk across the 
cognitive spectrum, ${ }^{5}$ but the point where an individual patient must consider driving cessation varies case by case. $^{2}$ Severe dementia is a contraindication to driving, and safe driving is generally unlikely in the presence of moderate dementia. Many patients with mild dementia and the majority with mild cognitive impairment may be deemed fit to continue driving but should be re-evaluated every $6-12$ months or sooner if indicated. ${ }^{2}$ Problems may arise due to shortcomings in the detection, diagnosis and disclosure of cognitive impairment: approximately $50 \%$ of older adults with dementia are either undiagnosed or unaware of the diagnosis. ${ }^{6}$

GPs' obligations with respect to $\mathrm{FtD}$ assessment and reporting differ across jurisdictions. In Ireland, the UK, Australia and parts of Canada, health professionals have an obligation to give clear advice to drivers in cases where an illness or an injury may compromise their $\mathrm{FtD}$, but the responsibility for notifying the licensing authority normally falls to the driver. ${ }^{7-10}$ Where a healthcare professional believes that a driver is not compliant with advice to stop driving or notify authorities, the healthcare professional has a duty to notify the authorities in the interests of public safety. In some US states and many Canadian jurisdictions, physicians are required to report directly to state licensing departments on patients who have specific medical conditions, including dementia. ${ }^{10}{ }^{11}$ Additionally, in Ireland, where this study took place, driving licences must be renewed after intervals of 1,3 or 10 years, depending on the age and health of the driver, and must be accompanied by a medical report in the case of injury or illness that may affect FtD. ${ }^{7}$ The medical report is generally signed by the patient's GP, and the requirement for this report is a trigger for many consultations on $\mathrm{FtD}$ in Irish general practice.

Qualitative research examining GPs' perspectives on FtD consultations for patients with possible cognitive impairment demonstrates that their discomfort with these consultations transcends differences in regional policies on licensing and road safety. ${ }^{12}$ Findings include GPs' view of themselves as reluctant regulators ${ }^{13}$ who 'hate' that driving assessment has anything to do with their role, ${ }^{14} 15$ and frequent uncertainty about their legal and ethical obligations. ${ }^{16-21}$ Evaluations of patients' responses to the prospect of driving cessation in the context of cognitive impairment highlight a range of negative emotions, such as anger, frustration and sadness, the disruption to self-identity and fear of loss of independence. ${ }^{22}{ }^{23} \mathrm{Up}$ to one-fifth of GPs report a patient leaving their practice because of FtD consultations that have gone badly, highlighting just how distressing these consultations can be for patients. ${ }^{21}$

International strategies for managing the rising global prevalence of cognitive impairment and dementia prioritise management in the community, and GPs are assuming an ever-increasing role in the ongoing management of these conditions, including the assessment and reassessment of medical FtD. ${ }^{24}$ However, there has been little examination of the consultation strategies used by
GPs in an effort to lessen the emotional impact of FtD consultations for patients with cognitive impairment, nor have patients' views on GPs' consultation strategies been explored. In this study, we examine both sides of the FtD consultation-GPs and patients with cognitive impairment-in order to understand how the negative aspects of these consultations may be mitigated. We were specifically interested in how, in the setting of cognitive impairment, FtD is introduced into consultations in primary care; what consultation strategies GPs use; the influences on GPs' approach; and aspects of the FtD consultation that could be improved from patients' and GPs' perspectives.

\section{METHODS}

A multiperspective qualitative design was used. The setting was primary care in Ireland.

\section{GP participants and interviews}

Semistructured qualitative interviews were conducted with GPs between February and July 2017. Inclusion criteria were fully trained GPs working in clinical practice. Participants were recruited via online GP discussion groups and two regional professional development meetings. We sought a maximum variation sample of GPs against the following criteria: length of time qualified (over/under 10 years), practice location (rural/urban) and practice size $(<3 / \geq 3$ full-time GPs). Recruitment continued until the sample represented a satisfactory mix of these criteria and preliminary data analysis indicated that further interviews were unlikely to generate additional information power. $^{25}$

During interviews, the researcher (KML) drew on the technique of chart-stimulated recall. ${ }^{26}$ This technique was adapted for research from the field of medical education and involves asking healthcare professionals to describe their management of a case and the reasoning behind the clinical decisions they had made, using the patient's medical chart as an aide-memoire to the narrative. The acceptability, reliability and validity of chart-stimulated recall for retrospectively assessing clinical practice have been demonstrated in previous studies. ${ }^{26}$ We asked participants to choose patients from their caseload for whom recent consultations on FtD included concerns about cognition and to refer to the notes they had made during the consultation when describing the index consultation and subsequent consultations with that patient. We asked GPs to choose at least two cases, ideally one where the FtD consultation went well and one where it did not go so well. This approach focused interviews on GPs' practice-based experience rather than on rhetorical discussions of $\mathrm{FtD}$, gave insight into the breadth of GPs' experience of FtD consultations in cognitive impairment, and facilitated exploration of both unsuccessful approaches and approaches that could be usefully implemented by others. Interviews were conducted in the GPs' practices to allow access to case notes and to facilitate recall of the consultations. ${ }^{26}$ 


\section{Patient participants and interviews}

Semistructured qualitative interviews were conducted with patients between June and November 2017. Inclusion criteria were patients with cognitive impairment (mild cognitive impairment or mild dementia). We invited patients to participate using mail-outs to people who had attended driving assessment services after being referred to that service by their GP due to concerns about cognitive impairment. As this initial recruitment strategy was, unfortunately, not very successful, we expanded recruitment by asking participating GPs to invite patients with cognitive impairment directly. Once a potential participant expressed interest in the study, the qualitative interviewers (KML and CSh) ensured that the person had a full understanding of the process and confirmed their capacity to participate. One person was interested in participating but suffered from aphasia as a feature of her cognitive impairment (although she was still deemed fit to drive after assessment); in this case, we offered the patient's family carer an opportunity to be interviewed instead. No personal identifying information was collected on the patients discussed by GPs, and there was no intentional overlap between the patients discussed by GPs and the patient participants.

We conducted interviews in the participant's home, the university or other location of their choice. A topic guide, which was written in collaboration with the Alzheimer Society of Ireland, was used in interviews (see online supplementary appendix 1): in summary, participants were asked to recount their experiences of, thoughts on and preferences for (or those of the person they care for) FtD consultations in primary care. Both interviewers (KML (PhD) and CSh (PhD)) had extensive experience in interviewing in sensitive situations in the fields of dementia and gerontology. None of the participants were known to the interviewers before the study commenced.

\section{Data analysis}

All interviews were audio-recorded, transcribed in full and de-identified. After the first five GP interviews and all patient interviews, the interviewers (KML and CSh) presented reflexive accounts and field notes to two other team members ( $\mathrm{CSi}$ and $\mathrm{CB}$ ), leading to iterative modification of topic guides. We used a framework approach to analysis. ${ }^{27}$ Once data collection was complete, each transcript was thematically coded by at least two members of the multidisciplinary research team (KML, health service researcher; $\mathrm{CSi}$, TF and $\mathrm{CB}$, all academic GPs; LH, occupational therapist; and CSh, social scientist) to familiarise ourselves with the data. We used this list of themes to create an inductive matrix for further analysis. The matrix placed emphasis on the GPs' approach to FtD consultations and the events that ensued within those consultations. After indexing interview data into the matrix, further rounds of coding were conducted to develop, interpret and refine themes within the matrix. Divergent accounts were sought within the data. Interviews with patients were analysed in a similar way but

\begin{tabular}{|c|c|c|c|}
\hline & $\begin{array}{l}\text { Practice } \\
\text { location }\end{array}$ & $\begin{array}{l}\text { Practice size at } \\
\text { time of interview } \\
\text { (small group } \\
<3 \text { full-time GPs/ } \\
\text { larger group } \\
\geq 3 \text { full-time GPs) }\end{array}$ & $\begin{array}{l}\text { Years qualified } \\
\text { as GP }\end{array}$ \\
\hline GP1 & Urban & Large group & Over 10 years \\
\hline GP2 & Urban & Small group & Less than 10 years \\
\hline GP3 & Rural & Small group & Less than 10 years \\
\hline GP4 & Rural & Large group & Over 10 years \\
\hline GP5 & Mixed & Large group & Less than 10 years \\
\hline GP6 & Rural & Large group & Over 10 years \\
\hline GP7 & Rural & Large group & Less than 10 years \\
\hline GP8 & Rural & Small group & Over 10 years \\
\hline GP9 & Urban & Large group & Over 10 years \\
\hline GP10 & Urban & Small group & Over 10 years \\
\hline GP11 & Urban & Small group & Less than 10 years \\
\hline GP12 & Urban & Small group & Less than 10 years \\
\hline
\end{tabular}

GP, general practitioner.

using a different matrix. The results from both matrices were merged and interpreted together in the final stage of the analysis.

Transcripts were not provided to participants for feedback. NVivo software was used to support data analysis. All participants provided written informed consent. The study report was written in adherence with the Consolidated Criteria for Reporting Qualitative Research checklist (online supplementary appendix 2).

\section{Patient and public involvement}

We developed the patient invitations, information letters and expression of interest forms in collaboration with patient and public representatives from the Alzheimer Society of Ireland. Patient and public representatives also reviewed and rephrased the topic guide for interviews with patients with cognitive impairment.

\section{Findings}

Eighteen people participated: 12 GPs, 5 people with cognitive impairment and 1 carer. The characteristics of GP participants are shown in table 1. Among patient participants, three patients lived in rural locations. One patient was awaiting review by driving assessment services, two had been deemed not fit to drive after assessment and the others had been deemed fit to drive after assessment. On average, GP interviews lasted $20 \mathrm{~min}$ (range 10-43) and patient interviews lasted $29 \mathrm{~min}$ (range 8-120). The themes are presented narratively incorporating quotes from the data (shown in italics).

Route to the consultation: shifting gears versus sudden stops The issue of FtD tended to arise in consultations in two ways. If cognitive impairment was acknowledged as a 
problem between the patient and their GPs, GPs reported introducing the topic of $\mathrm{FtD}$ into routine consultations to proactively prepare patients for future changes in driving status. This measured approach included use of warning shots that changes may be required, revisiting the issue over multiple consultations and signing medical reports for only 1 year at a time to alert the patient to the GP's concerns.

Sometimes what I will do, I will give the person a heads up and say, "Ok, I am going to certify you for the next year but be aware of the fact that in a year's time you may not be in a position to drive the car and you might need to think about getting someone else to do the driving for you. GP6

In contrast, in many cases, the issue of driving arose abruptly because of a patient's request for an urgent driving license medical report. If either pre-existing concerns about the patient's cognition had not been discussed openly with the patient or the specific issue of their driving had not been addressed with them previously, the FtD consultations could become contentious. Being confronted with the possibility of cognitive impairment and potential restrictions on their driving in the one encounter led to patients becoming upset and consultations becoming fraught. As GPs had no forewarning for the patient's reason for attendance and often had insufficient time to comprehensively review the patient's case during the $10 \mathrm{~min}$ consultation, they reported either making rapid decisions on the patient's FtD or deferred decision-making, meaning the patient would not be able to stay on the road until further evaluation was carried out.

I had not realized that she was driving until she asked me to sign the driving renewal form ... I was actually quite shocked that she was driving because it was clear to me that she was not... well anyway, I explained to her the reasons why I didn't think it was a good idea for her to drive and she was quite upset over that GP10

GPs described patient responses as furious (GP5), really unhappy (GP9), very upset (GP12), angry (GP3 and GP4), grumpy (GP2) and very cross (GP1). The patient's response led to reactive feelings of remorse or regret in GPs. Three GPs (GP1, GP4 and GP5) reported patients switching practice due to damaged physician-patient relationship after FtD consultations.

Patients themselves appeared guarded in their descriptions of the emotional impact of FtD consultations (with one clear divergent case who was openly frustrated and annoyed), despite reassurance of the independence of the research interviewer. However, during these interviews, the interviewers noted patients' non-verbal signs of frustration and sadness.

Well, I was a bit upset I suppose... (pause) .... my blood pressure increased. An anxiety I suppose. Patient 2 what am I going to do?... (I'm) not getting anywhere... (I'm) not accepting the report Patient 3

...you feel awful and it's really awkward and you've only 15 minutes. And then it is 'next!' It's actually terribly difficult. GP5

I was unable to sign his driving license application form on this occasion. And I never saw him again.... and that was 15 months ago. GP4

\section{Consultation strategies}

GPs reported drawing on a number of consultation and communication strategies when faced with this sensitive topic. They used these approaches both when adopting the proactive approach to introduce the patient to the idea of driving cessation and during the more acute consultations in an effort to reduce potential damage to the doctor-patient relationship.

\section{Reflecting and echoing}

A common approach reported by GPs was to echo patients' perceptions of their own road safety, their self-imposed restrictions and their level of comfort and confidence while driving back at them. In this way, GPs appealed to patients' remaining insight in an approach akin to motivational interviewing.

we started talking about him driving and I asked "Do you still feel comfortable to drive?" because - the word he used and I just echoed it was- sometimes he feels foggy. GP7

\section{Incorporating objective tests}

In an effort to prevent $\mathrm{FtD}$ decisions being viewed as doctor's discretion (GP1), GPs described using cognitive screening tools during consultations. Some GPs purposively added cognitive tests (such as the MiniCog, General Practitioner Assessment of Cognition (GPCOG) and the Mini-Mental State Examation (MMSE)) to their driving assessment proformas, to both prompt themselves to assess cognition and to "show" patients that cognitive assessment was necessary.

I added the Minicog to our template not so that people must use it but more to remind them GP9

\section{Blaming guidelines}

To protect the physician-patient relationship, many GPs 'blamed' the national driving guidelines in consultations where they were deferring or denying patients' medical certification to drive.

you can sort of externalize things - you know it's not me - it's them. I am just acting along these guidelines. It's not that I am saying you can't drive, it's the guidelines that say you can't drive. So you are depersonalizing things to some degree and you can continue the relationship with the patient ...erm...by blaming big brother! GP2 
While guidelines suggested different approaches for patients with mild cognitive impairment versus dementia, in practice, GPs did not see such a clear distinction between these conditions. Despite guidelines not always matching the reality of assessing FtD as GPs experienced it, they were still happy to have them as a prop to the consultation if they needed to.

If you're not happy with it, you are the one who actually has to defend yourself and sleep at night so .[...]. you try and use those [guidelines] like a resource GP12

\section{Shift responsibility to external assessors}

GPs reported referring patients for external driving assessment (eg, independent mobility assessment services, geriatricians, neurologists and old age psychiatrists) for three main reasons. Some GPs used these services as a means of protecting the physician-patient relationship while assessing or convincing patients of the need for driving cessation. Others needed reassurance in cases which were borderline (GP4 and GP9), due in part to the risk of litigation perceived by GPs if patients were subsequently involved in a road traffic accident. Lastly, many GPs reported referring patients because doing a satisfactory assessment can be very hard in a 10 or 15 min consultation (GP11). Access to these services was patchy, with most patients having to pay out of pocket, which some GPs felt introduced an element of inequity into care.

Her license came up for renewal and she lives 4 miles out the country so it was going to be a huge thing to say you can't. But I had sort of given her a few warning shots so when it came up for renewal I said "Look, I can't really make this decision now on my own. So that is why I referred her." GP8

Am I really going to make a cut off to say someone can't drive anymore? (Sighs)...If I am unsure then I would refer to the assessors. Do as I do... at least you are medico legally covered. GP3

Patients were confused about the role of external assessment, with some interpreting it as a sign of GPs' uncertainty about how to proceed. Other patients reported a preference for on-road assessment over being questioned about driving by their GP.

Well the ideal way to test a person driving is to go out with them in the car - that must be the greatest way there is rather than sitting there and asking me questions about driving because at my age anyway, asking questions about driving is more for young people who are more alert to all questions...used to exams and that. Patient 2

\section{The value of continuity}

Patients reported mixed feelings about having their GPs conduct FtD assessments, with some asking why GPs would be considered to know anything about a person's
FtD and another recognising the potential of FtD assessment to interfere negatively with the physician-patient relationship.

Well the doctor, what would the doctor know about your driving? Patient 4

I can understand a difficulty with a doctor that is your own doctor asking questions like that because the doctor could feel like...that he's causing a bit of a muddle between yourself and himself which shouldn't happen at all. Doctor and patient need to get on and maybe it isn't appropriate for a doctor to be doing that. Patient 2

However, patients were consistent in their view that if medical assessment of FtD is to remain the duty of GPs, then it should be with their own GP and not with a locum or an unfamiliar GP. They felt their own long-standing GP would have a better 'sense' of them and discuss FtD without causing alarm.

The scenario would never have arisen if it was her own doctor. She is capable of driving, her problem is her communication, and that doesn't affect her driving ability. Carer 1 discussing her aunt who was subsequently deemed fit to drive

Correspondingly, GPs working in the one practice for many years felt that continuity of care helped them to identify signs of cognitive impairment early and facilitated discussions with patients before a crisis developed. This approach supported patient involvement in plans for driving cessation while also allowing them to continue driving for as long as was safely possible.

It took about three consultations before we got around to it [discussing driving] head on GP1, working in the one practice for more than ten years.

Discussion re: driving seems ok at present but advised likely to need to stop soon. GP9 reading from her notes.

In contrast, recently qualified GPs, new GPs in a practice and locums were less likely to sign patients off as fit to drive, tending instead to first discuss cases with colleagues or refer for external assessments. GPs reported the greatest difficulties when they were working as locums because they encountered patients to whom they were essentially strangers without any warning of what the consultation would be about. Having not anticipated any reluctance to sign the medical report, patients could then understandably become aggravated in the consultation.

someone comes in and they present a form for driving with no warning, no preparation for it, and often you have never met them before.... she nearly lunged at me when I said to her that I don't know if I can sign it. She nearly jumped across the table and she said "How am I supposed to do my shopping? GP5 


\section{The road ahead: what needs to change}

\section{Mapping the journey}

Patients wanted their GPs to explain clearly why there were concerns about their driving and the reasons behind the decisions they had made. Patients recognised that external driving assessment was for the benefit of public road safety, but requested that they be told what to expect from the assessment and what steps would follow. Patients also felt that the plan should move quickly so that they would not be off the road for an unnecessarily long duration.

Well I would like them to sit down and explain things to people. .... To say your memory isn't the best and it would be safer if you didn't drive. Researcher: Would that be better if he had just come out and said that? Patient: I think so...I said ' I have a 16 (new) car in my drive.' and he said 'you will probably be back driving again' Patient 5 who was found unfit to drive in her driving assessment

we were totally...we actually didn't know about it [driving assessment] before so it was totally new, I didn't know of anyone who had it done before Carer 1

\section{Walk in the patient's shoes}

Patients spoke of the huge emotional impact that driving cessation would have on their lives, including constricted social opportunities, loneliness and increased dependence on family and neighbours. Although it was evident that GPs recognised this emotional impact, it appeared that they had not acknowledged or helped patients deal with it sufficiently, and this added to the upset that patients had experienced.

If I couldn't drive, well I'd feel loneliness actually, it is something I would feel. I am single you know Patient 2

Patient: He said he just couldn't sign it, and that was it.

Interviewer: Were you satisfied with the information he gave you?

Patient: No certainly not...I was annoyed...[...]...I don't want to be dependent on my children to go places, I was always able to get into my car and drive... now I have to get one of the girls to drive me down, and that's not on. Patient 5

\section{Increase two-way traffic between GPs and licensing system}

To ease the discomfort associated with the task of assessing medical FtD, GPs called for better lines of communication from the national driving authority and resources to support longer, more comprehensive assessment in their practices. For instance, recent changes had been introduced to the medical report, allowing for restricted driving for patients (licences to drive short distances, in local areas and during daylight hours), but participating GPs reported they had not received instruction on how they should make decisions on restricted driving, leaving them feeling undermined in the consultation.

I suppose you have heard that the driving licence forms miraculously changed this week. Nobody told us. The first we knew was when a patient came in clutching the form and we were looking at it. GP1

\section{DISCUSSION}

In this multiperspective qualitative study, we found that where cognitive impairment has already been discussed openly with a patient in primary care, GPs can use relational continuity to prevent or mitigate patients' emotional response to the threat of driving cessation. Where cognitive impairment is known, GPs can revisit the issue of driving over multiple consultations and use nuanced communication strategies to maintain some sense of patient autonomy and to engage them in planning for driving cessation before a crisis develops. However, the abrupt introduction of concern about cognition when patients present for medical driving reports is problematic. Being confronted with unanticipated hesitations about FtD while simultaneously learning of the possibility of cognitive impairment represents a double whammy for patients, which understandably leads to consultations becoming heated.

\section{Comparison with existing literature}

Similar to others, ${ }^{20}$ we found that patients themselves rarely raise the issue of driving in a proactive way, unless attending to get medical reports signed. In Canada, a campaign called 'Not If but When' encourages GPs to introduce the topic of driving early in the course of caring for an older adult with dementia. ${ }^{28}$ We would extend on this recommendation by suggesting that driving is also discussed in routine follow-up of patients with mild cognitive impairment.

Prior studies of older adults' communication preferences for driving cessation, although they were not focused specifically on cognitive impairment, have similarly identified that communication should occur over a period of time rather than suddenly, as well as the importance of maintaining older adults' agency in the decision to stop driving. ${ }^{23}{ }^{29-32}$ Betz et al have suggested that the latter could be achieved via advance driving directives. ${ }^{29} 30$

Patients with cognitive impairment can react to recommendations to stop driving with shock, anger and denial. ${ }^{33}$ Our study builds on others to show how this emotional turmoil may be mitigated not only by addressing driving early but also by addressing it separately from the disclosure of diagnosis of cognitive impairment. ${ }^{34}$ Following this, patients in this study accepted the need for driving assessment to determine their FtD but wanted clear information on what to expect from driving assessment and what will follow.

As with any loss, driving cessation may elicit a grief reaction, amplified by the potential changes in independence, 
status and social interaction. ${ }^{2233}$ While GPs are well placed to guide and offer compassionate support to patients through these adjustments, ${ }^{35}$ we found that their current efforts seem to fall short of patients' expectations; patient participants requested more empathy and acknowledgement for the impact of driving cessation on their quality of life.

\section{Strengths and limitations}

The transferability of our findings is enhanced by our sample of GPs and patients, which represents diverse professional characteristics and a range of perspectives. However, each of these perspectives represents only one of the multiple truths that can exist for these consultations. Direct observation or recording of consultations would have generated a different perspective and may have added further insights into the conduct and content of these challenging doctor-patient interactions. The credibility of our findings is supported by triangulation of GP data with patient experiences and use of chart-stimulated recall in GP interviews. Chart-stimulated recall focused conversations on GPs' practice-based experience of FtD consultations rather than rhetoric or views. We used peer debriefing to bring reflexivity and sensitivity to data collection, while data analysis harnessed multidisciplinary involvement in every iteration.

Similar to other teams, we found that engaging older patients with cognitive impairment in our research was challenging. ${ }^{36}$ When we encountered low participation rates initially, we expanded our recruitment strategies. The level of patient engagement was still somewhat disappointing, but the diversity of patients who did participate enhanced the robustness of our findings, as did the recurrence of themes in the data.

Some patient participants appeared cautious about the detail they provided, despite reassurance of the independent nature of the research interviewer. That this occurred despite enrolling only patients with sufficient capacity to consent to participate in the study, and using the professional skills of both interviewers, indicates just how sensitive a topic FtD in cognitive impairment is.

\section{Implications for practice, policy and future research}

Across the spectrum of mild cognitive impairment to early dementia, many patients remain safe to drive. ${ }^{37}$ However, in light of the increasing prevalence of these conditions, our findings offer suggestions to support assessment of medical FtD for people with cognitive impairment in primary care. First, due to the sensitive nature of FtD consultations, it is preferable that patients see their regular GP for FtD assessments. We identified that this sensitive topic is not suitable for review by locum doctors; it requires the full strength of relational continuity that primary care has the potential to offer. This requires policy and procedures at practice level and could be further encouraged by having a requirement on the medical report form to say how long the assessing physician has known the patient.
A second recommendation is that a discussion of driving should be introduced into routine consultations for all patients with cognitive impairment, even in the absence of apparent functional impairment. For patients with established dementia, FtD discussions should be incorporated into routine postdiagnosis management, along with discussion of other legal issues, such as willmaking and advanced care directives. ${ }^{30}$ By taking a proactive approach to driving, healthcare professionals may avoid the distress associated with an unanticipated yet imminent threat of driving cessation. Engendering a sense of agency, input and control over their own plans for driving cessation may also help patients adjust better to these changes. ${ }^{22}$ This approach requires that GPs engage in open communication, early disclosure, education and support for patients with cognitive impairment and dementia, in line with the recommendations of several international guidelines. ${ }^{38}$ Further, promotion of early and open conversation about FtD by the lay media, patient advocacy groups and healthcare professionals may prompt better discussions about driving between patients and their physicians. ${ }^{1328}$

The point where driving cessation is indicated for a patient with dementia represents an important and emotional transition in their illness. Patient and caregiver accounts identify driving cessation as one of a series of losses in dementia and represent a point of transition in the illness to increasing dependence, reduced social participation and a negative view of one's self. ${ }^{22}$ Empowering GPs to address patients' psychological and emotional responses of loss and grief will require advanced communication skills, especially in the context of cognitive impairment, where patient insight may be impaired. However, existing educational resources in FtD have been criticised for lack of applicability. ${ }^{141639} \mathrm{We}$ suggest that future educational resources frame consultations where driving cessation may be indicated as involving non-bereavement loss and draw on communication skills traditionally associated with breaking bad news. ${ }^{33} 40$ We also recommend that existing educational programmes on the management of cognitive impairment highlight the benefit of addressing, diagnosing and disclosing cognitive impairment early with patients, and empower GPs to adopt a proactive approach that facilitates maintenance of a patient's autonomy for as long as is safely possible.

Where uncertainty about a patient's FtD exists, or additional evidence is needed to convince a patient that they are no longer fit to drive, assessment by third parties such as occupational therapists or specialist physicians can be helpful. However, in Ireland and elsewhere, ${ }^{21}{ }^{41}$ many patients face geographical and/or financial barriers to accessing such services. Providing universal access to assessment services would better support GPs in making decisions on FtD and communicating these decisions to patients. 


\section{CONCLUSION}

GPs used their longitudinal relationship with cognitively impaired patients to reduce the potential for conflict in consultations on FtD. These efforts could be augmented by explicit discussion of cognitive impairment at an earlier stage for all patients affected by cognitive impairment from mild cognitive impairment right through to dementia. Patients would benefit from greater input into planning driving cessation and acknowledgement from their GPs of the impact this may have on their quality of life.http://dx.doi.org/10.1136/bmjopen-2018-024452

Acknowledgements We would like to acknowledge the input and support of the Alzheimer Society of Ireland and the patient and public representatives of that organisation, and the time taken by general practitioners and patients to participate in this study.

Contributors CSi, TF, CB and LH planned the original study, wrote the protocol, won funding and oversaw the original study. CSi, TF, CB, KML, CSh and LH designed, planned and carried out analyses for this paper. CSi drafted this manuscript and revised it in response to critical revisions from all authors. CSi and $\mathrm{CB}$ are the co-guarantors of the study. All authors read and approved the final manuscript.

Funding This work was supported by the Road Safety Authority of Ireland Research Grant in Traffic Medicine (2016). CSi is funded via a National Institute of Health Research (NIHR) Clinical Lecturer award. Funding sources had no role in the design, analysis or writing of the manuscript for this study. The views expressed are those of the authors and not necessarily those of the Road Safety Authority or the NIHR.

Competing interests None declared.

Patient consent for publication Obtained.

Ethics approval Research ethics approval was granted by the Clinical Research Ethics Committee of the Cork Teaching Hospitals (ECM 4 (aa) 06/09/16)

Provenance and peer review Not commissioned; externally peer reviewed.

Data availability statement Data are available upon reasonable request.

Open access This is an open access article distributed in accordance with the Creative Commons Attribution Non Commercial (CC BY-NC 4.0) license, which permits others to distribute, remix, adapt, build upon this work non-commercially, and license their derivative works on different terms, provided the original work is properly cited, appropriate credit is given, any changes made indicated, and the use is non-commercial. See: http://creativecommons.org/licenses/by-nc/4.0/.

\section{REFERENCES}

1. Carr DB, O'Neill D. Mobility and safety issues in drivers with dementia. Int Psychogeriatr 2015;27:1613-22.

2. Rapoport MJ, Chee JN, Carr DB, et al. An international approach to enhancing a national guideline on driving and dementia. Curr Psychiatry Rep 2018;20:16.

3. Iliffe S, Manthorpe J, Eden A. Sooner or later? issues in the early diagnosis of dementia in general practice: a qualitative study. Fam Pract 2003;20:376-81.

4. Petersen RC, Roberts RO, Knopman DS, et al. Mild cognitive impairment: ten years later. Arch Neurol 2009;66:1447-55.

5. Fraade-Blanar LA, Ebel BE, Larson EB, et al. Cognitive decline and older driver crash risk. J Am Geriatr Soc 2018;66:1075-81.

6. Moore V, Cahill S. Diagnosis and disclosure of dementia--a comparative qualitative study of Irish and Swedish General Practitioners. Aging Ment Health 2013;17:77-84.

7. Road Safety Authority. Sláinte agus Tiomáint medical fitness to drive guidelines (group 1 and 2 drivers, 2019.

8. UK driver and vehicle licensing agency. Available: https://www.gov. uk/guidance/general-information-assessing-fitness-to-drive\#dvlanotification-by-drivers-or-healthcare-professionals [Accessed 6 Jun 2019].

9. Austroads. Assessing fitness to drive. Available: https://austroads. com.au/drivers-and-vehicles/assessing-fitness-to-drive/for-healthprofessionals2016 [Accessed 6 Jun 2019].
10. US National Highway Traffic Safety Administration. Physicians guide to assessing and counselling older drivers, chapter 8. Available: https://www.nhtsa.gov/staticfiles/nti/older_drivers/pdf/811298. pdf2009 [Accessed 6 Jun 2019].

11. Canadian Medical Protective Association. Fitness to drive: when do physicians have a duty to report? 2015. Available: https://www. cmpa-acpm.ca/en/advice-publications/browse-articles/2015/fitnessto-drive-when-do-physicians-have-a-duty-to-report [Accessed 6 Jun 2019].

12. Berger JT, Rosner F, Kark P, et al. Reporting by physicians of impaired drivers and potentially impaired drivers. J Gen Intern Med 2000;15:667-72.

13. Friedland J, Rudman DL, Chipman M, et al. Reluctant regulators: perspectives of family physicians on monitoring seniors' driving. Top Geriatr Rehabil 2006;22:53-60.

14. Hum S, Cohen C, Persaud M, et al. Role expectations in dementia care among family physicians and specialists. Can Geriatr J 2014;17:95-102.

15. Jones K, Rouse-Watson S, Beveridge A, et al. Fitness to drive - GP perspectives of assessing older and functionally impaired patients. Aust Fam Physician 2012;41:235-9.

16. Snellgrove CA, Hecker JR. Driving and dementia: general practitioner attitudes, knowledge and self-reported clinical practices in South Australia. Australas J Ageing 2002;21:210-2.

17. Hoggarth PA. Diagnosis of cognitive impairment and the assessment of driving safety: a survey of Canterbury GPs. $N Z$ Med $J$ 2013;126:87-97.

18. Hill LL, Rybar J, Styer T. Evaluation of curriculum to improve health professionals' ability to manage age-related driving impairments. Accid Anal Prev 2013;61:222-32.

19. Meuser TM, Carr DB, Berg-Weger M, et al. Driving and dementia in older adults: implementation and evaluation of a continuing education project. Gerontologist 2006;46:680-7.

20. Moorhouse P, Hamilton L, Fisher T, et al. Barriers to assessing fitness to drive in dementia in nova Scotia: informing strategies for knowledge translation. Can Geriatr J 2011;14:61-5.

21. Doherty U, Hawke AL, Kearns J, et al. Fitness to drive in cognitive impairment-a quantitative study of GPs' experience. Irish medical journal 2015;108:112-4.

22. Sanford S, Rapoport MJ, Tuokko H, et al. Independence, loss, and social identity: perspectives on driving cessation and dementia. Dementia 2018:1471301218762838.

23. Johnson DA, Frank O, Pond D, et al. Older people with mild cognitive impairment -- their views about assessing driving safety. Aust Fam Physician 2013;42:317-20.

24. Prince MJ, Wimo A, Guerchet MM. World Alzheimer report 2015. the global impact of dementia. An analysis of prevalence, incidence, cost and trends. London: Alzheimer's Disease International (ADI), 2015.

25. Malterud K, Siersma VD, Guassora AD. Sample size in qualitative interview studies: guided by information power. Qual Health Res 2016;26:1753-60.

26. Sinnott C, Kelly MA, Bradley CP. A scoping review of the potential for chart stimulated recall as a clinical research method. BMC Health Serv Res 2017;17:583.

27. Ritchie J, Lewis J. Qualitative research practice: a guide for social science students and researchers. California USA: Sage, 2003.

28. Moorhouse P, Hamilton LM. Not if, but when: impact of a driving and dementia awareness and education campaign for primary care physicians. Can Geriatr J 2014;17:70-5.

29. Betz ME, Scott K, Jones J, et al. "Are you still driving?" Metasynthesis of patient preferences for communication with health care providers. Traffic Inj Prev 2016;17:367-73.

30. Betz ME, Jones J, Petroff E, et al. "I Wish We Could Normalize Driving Health:" A qualitative study of clinician discussions with older drivers. J Gen Intern Med 2013;28:1573-80.

31. Perkinson MA, Berg-Weger ML, Carr DB, et al. Driving and dementia of the Alzheimer type: beliefs and cessation strategies among stakeholders. Gerontologist 2005;45:676-85.

32. Adler G, Rottunda S, Kuskowski M. Dementia and driving. Clin Gerontol 1999;20:23-34.

33. Liddle J, Bennett S, Allen S, et al. The stages of driving cessation for people with dementia: needs and challenges. Int Psychogeriatr 2013;25:2033-46.

34. Byszewski AM, Molnar FJ, Aminzadeh F. The impact of disclosure of unfitness to drive in persons with newly diagnosed dementia: patient and caregiver perspectives. Clin Gerontol 2010;33:152-63.

35. Harvey JH, Miller ED. Toward a psychology of loss. Psychol Sci 1998;9:429-34.

36. McMurdo MET, Roberts $\mathrm{H}$, Parker S, et al. Improving recruitment of older people to research through good practice. Age Ageing 2011;40:659-65. 
37. Breen DA, Breen DP, Moore JW, et al. Driving and dementia. BMJ 2007;334:1365-9.

38. Ngo J, Holroyd-Leduc JM. Systematic review of recent dementia practice guidelines. Age Ageing 2015;44:25-33.

39. Byszewski AM, Graham ID, Amos S, et al. A continuing medical education initiative for Canadian primary care physicians: the driving and dementia toolkit: a pre- and postevaluation of knowledge, confidence gained, and satisfaction. J Am Geriatr Soc 2003:51:1484-9.

40. Ungar L, Alperin M, Amiel GE, et al. Breaking bad news: structured training for family medicine residents. Patient Educ Couns 2002;48:63-8.

41. Betz ME, Jones J, Genco E, et al. Perspectives on tiered older driver assessment in primary care settings. Gerontologist 2016;56:272-81. 